\title{
Análise estatística dos parâmetros geotécnicos dos resíduos de construção e demolição reciclados (RCD-R) produzidos na região metropolitana do Recife-PE
}

Filho, J. A. C. S.

Escola Politécnica de Pernambuco Universidade de Pernambuco 50.720-001 - Recife, Brasil joao_albertof@hotmail.com
Santos, E. C. G.

Escola Politécnica de Pernambuco

Universidade de Pernambuco

50.720-001 - Recife, Brasil

Resumo Para viabilizar a utilização dos resíduos de construção e demolição reciclados $(R C D-R)$ em obras geotécnicas é necessário realizar ensaios de caracterização a fim de se conhecer as características deste resíduo. Pensando nisto, foram realizadas coletas de amostras de RCD-R Misto em usina de reciclagem em intervalos de 15 dias. Os resultados revelaram que o $R C D-R$ possue excelentes parâmetros geotecnicos e baixa variabilidade destes, o que possibilita a sua aplicação na Engenharia Geotécnica.

Abstract In order to enable the use of recycled construction and demolition waste (RCDW) in geotechnical works it is necessary to carry out the characterization tests to better understand the characteristics of this residue. Bearing in mind this proposal, samples of Mixed RCDW were collected at a recycling plant in intervals of 15 days. The results revealed that RCDW has excellent geotechnical properties with low coefficient of variability which makes possible its use in Geotechnical Engineering. 


\section{Introdução}

Neste artigo estão presentes os resultados dos ensaios de caracterização de sete amostras coletadas em usina de reciclagem de resíduos de construção e demolição reciclados (RCD-R) do tipo Misto.

\section{Materiais e métodos}

Este artigo contempla a parte experimental da pesquisa. Nesta parte realizou-se os ensaios de caracterização para obter os parâmetros geotécnicos do RCD-R coletado. Foram realizados os seguintes ensaios: análise granulométrica, composição gravimétrica, ensaio de compactação com energia Proctor Normal, massa específica dos grãos, limite de liquidez e plasticidade.

\section{Resultados}

\subsection{Estilos}

Na Figura 1 é possível notar que as curvas apresentam baixa variabilidade e que se trata de um material arenoso.

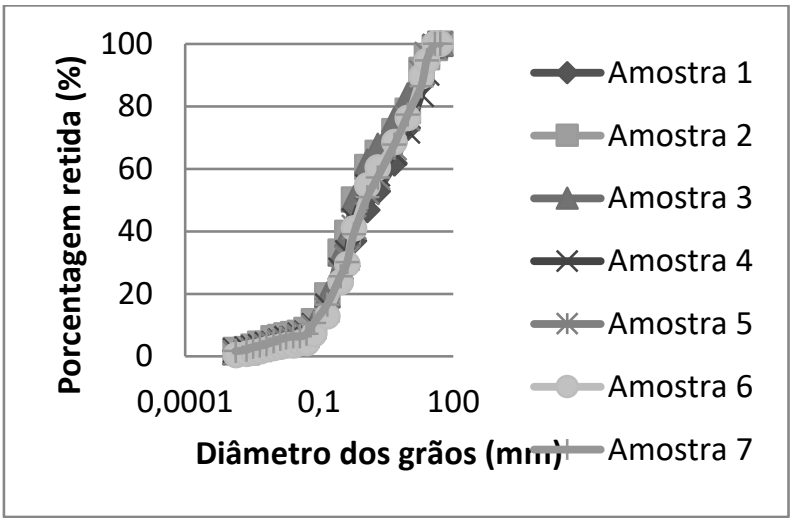

Fig 1. Curvas da análise granulométrica

\subsection{Composição gravimétrica}

De modo a melhor entender o comportamento mecânico dos RCD-R foi realizada a sua análise da composição gravimétrica, obtendo-se a participação de cada material presente na composição do RCD-R (Fig. 2 a 8).

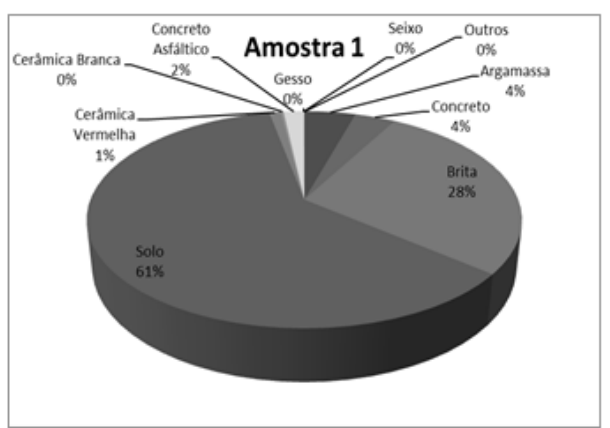

Fig 2. Composição Amostra 1

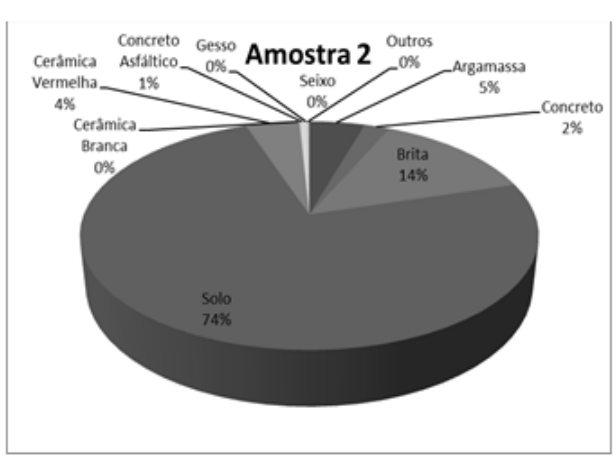

Fig 3. Composição Amostra 2

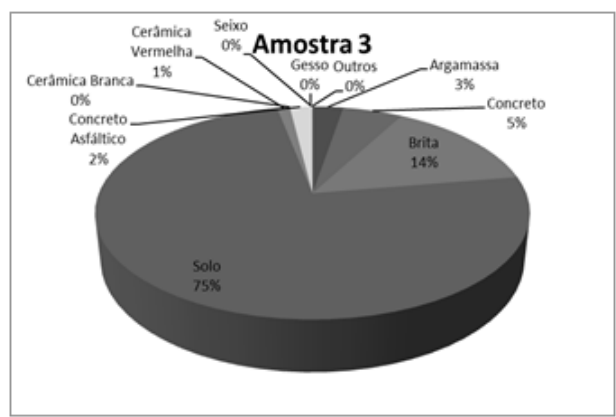

Fig 4. Composição Amostra 3

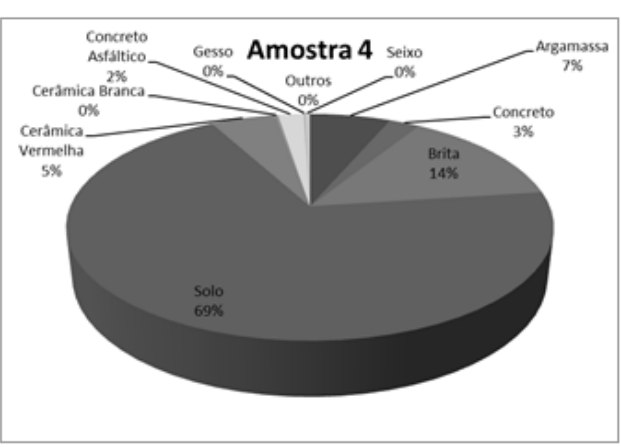

Fig 5. Composição Amostra 4 


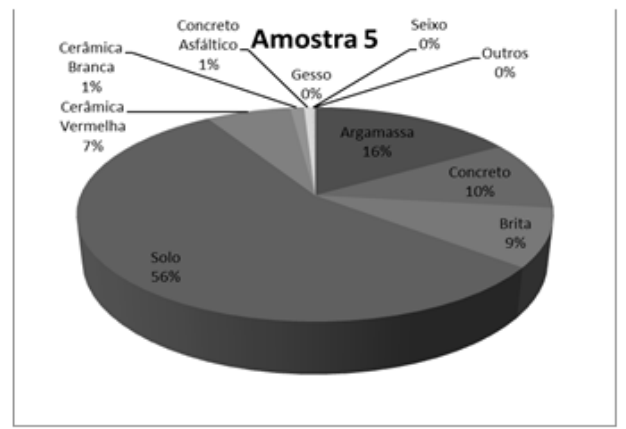

Fig 6. Composição Amostra 5

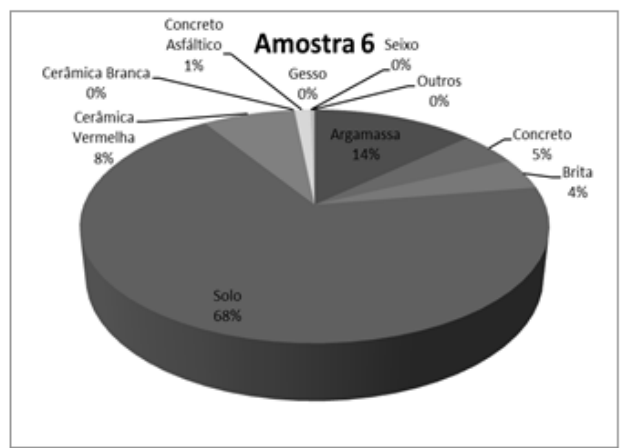

Fig 7. Composição Amostra 6

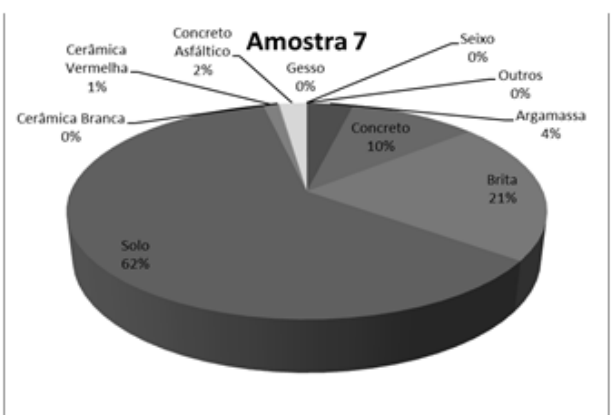

Fig 8. Composição Amostra 7

Os resultados dos ensaios de composição gravimétrica revelaram que o solo é o material predominante na massa do RCD-R ensaiado, apresentando valores percentuais superiores a $50 \%$. Tal resultado demonstra que o material ensaiado possue características que o tornam ideal para obras geotécnicas.

\subsection{Ensaio de compactação}

Tendo em vista o propósito de empregar os RCD-R em obras geotécnicas, foram realizados ensaios de compactação Proctor Normal, os quais forneceram os valores de massa específica aparente seca máxima e a umidade ótima de cada uma das amostras (Fig. 9).

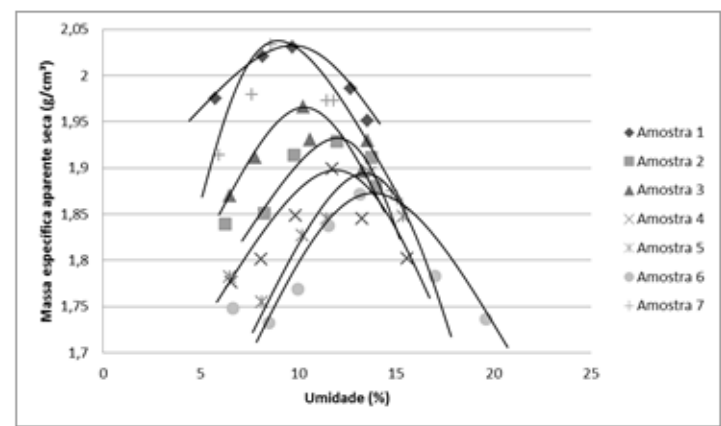

Fig 9. Curvas das compactações

As curvas de compactação permitem obter um valor médio de aproximadamente $1,5 \mathrm{~g} / \mathrm{cm}^{3}$ para massa específica aparente seca máxima e de $11 \%$ para umidade ótima.

\subsection{Ensaio de compactação}

O resultado do ensaio de massa específica dos grãos revelou que as amostras de RCD-R ensaidas apresentaram um valor médio de $2,7 \mathrm{~g} / \mathrm{cm}^{3}$, com um coeficiente de variação igual a $1,4 \%$.

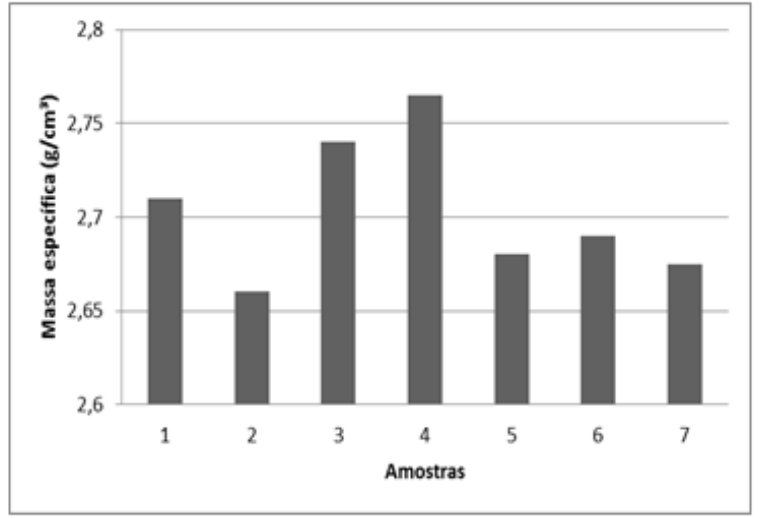

Fig 10. Massas específicas

\subsection{Limites de consistência}

A realizações dos ensaios de limite de consistência (LL e LP) revelaram que todas as amostras ensaiadas apresentam um comportamento não plástico, confirmando os resultados da análise granulométrica, que revelaram que o RCD-R ensaiado trata-se de um material que pode ser classificado como arenoso. De acordo com Santos (2007), esse é um ponto positivo para os RCD-R ao se levar em consideração as recomendações das normas BS 8006 e FHWA 2001, as quais sugerem o uso de materiais que não apresentam parcela de resistência coesiva na construção de estruturas de solo reforçado. 


\section{Materiais e métodos}

De posse dos resultados, observou-se que o RCD-R ensaiado é composto predominantemente por solo - percentuais de solo acima de $50 \%$ em todas as amostras ensaiadas. A análise granulométrica demonstrou que o RCD-R ensaiado pode ser classificado como uma areia pedregulhosa. Tal resultado foi confirmado por meio dos ensaios de limite de consistência, os quais revelaram o comportamento não plástico do material ensaiado. As análises das curvas de compactação Proctor Normal e dos ensaios de massa específica dos grãos revelaram que o RCD-R ensaiado possue excelentes parâmetros geotécnicos, com baixos coeficientes de variação. Conclui-se que os excelentes resultados obtidos na caracterização geotécnica do RCD-R ensaiado e baixa variabilidade dos seus parâmetros tornam possível a aplicação desse material em diversas obras geotécnicas.

\section{Referências}

[1] BRITISH STANDARD (1995). BS 8006: Code of practice for strengthened/reinforced soils and other fills.

[2] E.C.G. SANTOS, "Aplicação de resíduos de construção e demolição reciclados (RCD-R) em estruturas de solo reforçado", São Carlos, Universidade de São Paulo, 2007, 173p.

[3] ELIAS, V.; CHRISTOPHER, B.R.; BERG, R.R. (2001). Mechanically Stabilized Earth Walls and Reinforced Soil Slopes Design \& Construction Guidelines. U.S. Department of Transportation, Federal Highway Administration, Publication No.FHWA-NHI-00-043, 394p. 